\title{
Exchange Rate Determination and Forecasting: Can the Microstructure Approach Rescue Us from the Exchange Rate Disparity?
}

\author{
Guangfeng Zhang, ${ }^{1}$ Qiong Zhang, ${ }^{2}$ and Muhammad Tariq Majeed ${ }^{3}$ \\ ${ }^{1}$ GREQAM, School of Economics, Aix-Marseille University, Marseille 13236, France \\ ${ }^{2}$ School of Public Administration, Sichuan University, Chengdu 610000, China \\ ${ }^{3}$ School of Economics, Quaid-i-Azam University, Islamabad 45320, Pakistan \\ Correspondence should be addressed to Guangfeng Zhang; guangfeng.f.zhang@gmail.com
}

Received 21 August 2013; Accepted 1 December 2013

Academic Editors: M. E. Kandil and A. Rodriguez-Alvarez

Copyright (C) 2013 Guangfeng Zhang et al. This is an open access article distributed under the Creative Commons Attribution License, which permits unrestricted use, distribution, and reproduction in any medium, provided the original work is properly cited.

\begin{abstract}
Using two measures of private information and high-frequency transaction data from the leading interdealer electronic broking system Reuters D2000-2, we examine the association between exchange rate return and contemporaneous order flow and the predictability power of lagged order flow on the future exchange rate return. Our empirical analysis demonstrates that at high frequency $(5,10,15,20,25$, and $30 \mathrm{~min})$ there exists strong positive association between exchange rate returns and contemporaneous order flow. However, the results indicate weak predictability of order flow on the future exchange rate return.
\end{abstract}

\section{Introduction}

In exchange rate economics one conventional common sense about exchange rates is that exchange rates follow a random walk process for frequencies less than annual, such as daily, weekly, or even monthly. However, exchange rates show some trend, cyclicality, or general history dependence at lower frequencies. In contrast to macroeconomic fundamental analysis at lower frequencies, studies on microstructure approaches to exchange rates focus on the movements in exchange rates at high frequency. In particular, microstructure approaches emphasize how exchange rates respond to order flow, which measures the net transaction pressure between buy and sell forces in the actual FX market.

The theoretical frameworks for microstructure approaches to exchange rates have been sequentially built by Lyons [1] and Evans and Lyons [2]. In particular, the portfolio-shift model proposed by Evans and Lyons [2] is initially set up in a customer-dealer trading environment to show how order flow impacts exchange rates. Evans and Lyons apply the trading model to daily data obtained from the customer-dealer transaction platform Reuters D2000-1 to examine the exchange rate Deutsche mark/US dollar and Japanese yen/US dollar over May 1 to August 31, 1996. As a result, Evans and Lyons find that order flow can be a good series to determine the exchange rate movement at daily frequency. Similarly, empirical studies have applied this theoretical framework to various high-frequency data from diverse interdealer trading platforms. Killeen et al. [3] study the daily exchange rate German mark/French franc traded on the electronic broking system (EBS) in 1998. Hau et al. [4] study EBS data over 1998 to 1999 on the exchange rate German mark against US dollar. Berger et al. [5] study the intraday EBS data on the exchange rate US dollar/Japanese yen and Euro/US dollar spanning over January 1999 to February 2004. Ito and Hashimoto [6] study the intraday EBS data on the exchange rate US dollar/Japanese yen over January 4, 1998 to October 31, 2003 and Euro/US dollar over January 3, 1999 to October 31, 2003. Relevant studies also have examined the data from central banks. Rime [7] applies weekly data from Norges Bank for the exchange rate Deutsche mark/US dollar, British pound/US dollar, and Swiss franc/US dollar over July 1995 to September 1999. Payne [8] employs the tick-by-tick real-time foreign 
exchange trading data of Deutsche mark/US dollar from the interdealer FX trading system Reuters D2000-2. Overall, these studies consistently confirm a significant positive association between exchange rates and the corresponding contemporaneous order flow.

We aim to revisit the association between exchange rates and contemporaneous order flow and the predictability of the lagged order flow on the future exchange rate. Our study uses the intraday high-frequency transaction data from one of the leading interdealer electronic broking systems, Reuters D2000-2. We implement the empirical analysis via two different measures of order flow. Our analysis demonstrates that at high frequency $(5,10,15,20,25$, and $30 \mathrm{~min})$ there exists a strong positive association between exchange rate return and contemporaneous order flow. However, our empirical study shows weak predictability of order flow on the future exchange rate return. We also investigate the feedback trading in the FX market, but in our case this common theoretical hypothesis is rejected in our empirical analysis.

Comparing with relevant researches, our study is distinct from others in terms of the approach to measure order flow, the approach to implement the contemporaneous association and future prediction, and our particular data set. First, we use two different measurements of order flow to identify the impact of order flow on the contemporaneous exchange rate and the prediction of order flow on the future exchange rate. Related researches usually adopt the number of the net transactions (number of buyer-initiated trade minus number of seller-initiated trade) to proxy the absolute value of order flow, which is originally defined as the net value between the buyer-initiated trade and seller-initiated trade. We use the net transaction values in our empirical study though the number of transactions is adopted in relevant studies. In particular, in our empirical analysis, we also use the ratio of the absolute order flow to the trade flow to proxy order flow. Second, we examine the possible endogeneity of the contemporaneous order flow from the feedback trading and possible nonlinearity involved in the association. Third, we separately examine the contemporaneous determination of the exchange rate and the prediction power of the lagged order flow on the future exchange rate return. In the analysis of prediction, we identify the relative weak predictability of the history order flow on the future return, the weak historical dependence of order flow, and the high market efficiency in the actual FX market. Finally, it is worth mentioning that we use the transaction data for the exchange rate Deutsche mark/US dollar from one of the leading brokered interdealer trading system, Reuters D2000-2. Relevant researches have extensively examined the transaction data from customerdealer platform, central banks, direct interdealer transaction platform Reuters D2000-1, and broker interdealer transaction platform EBS. As we discussed in the survey section that the data from different source usually represent different characteristics of the trading agents in the FX market, which makes the association using the data from this different source worth revisiting.

The structure of this paper is as follows. Section 2 briefly introduces the theoretical issue about the association between exchange rates and order flow. Section 3 describes the data and constructs the series used in our empirical analysis. Section 4 introduces the methodology arrangements adopted in our empirical study. Section 5 reports the results of our empirical studies. Section 6 concludes this paper.

\section{Theoretical Issue}

The theoretical models proposed by Lyons [1] and Evans and Lyons [2] are designed to fit the structure of the actual foreign exchange trading process. The two models are termed as, respectively, hot-potato trading and portfolio-shift model. Particularly, Evans and Lyons [2] frame the real marketmarkers' behaviours in the FX market. Their model captures the important aspects of exchange rate determinations caused by the actual foreign exchange transactions between the market participants. For more details about the model details, see Lyons [1] and Evans and Lyons [2]. We summarize the relationship between the exchange rate return $\Delta p_{t}$ and the order flow $x_{t}$ in the specification as follows:

$$
\Delta p_{t}=\alpha+\beta x_{t}+\varepsilon_{t}
$$

As the theoretical model suggested, the positive net transaction pressure between buying and selling increases the value of the exchange rate which is defined as the domestic price of the foreign currency. The coefficient $\beta$ on order flow $x_{t}$ should take positive value. On the contrary, the negative net transaction pressure decreases the value of the exchange rate. As to the association between exchange rate return $\Delta p_{t}$ and order flow $x_{t}$, practical studies are concerned with the causation relationship between these two series. Representative studies, such as those of Killeen et al. [3] and Payne [8], use the VAR structure and Johansen cointegration procedure to examine the long-run association involved. They demonstrate a longrun cointegration relationship between exchange rates and order flow, but a single direction of causality from order flow to the exchange rate return. According to the theoretical framework of Evans and Lyons [2], our empirical study examines the impact of order flow on the contemporaneous exchange rate return and the predictability of order flow on the future exchange rate return.

\section{Data Description and Construction}

Our empirical analysis uses the real transaction data for the exchange rate Deutsche mark/US dollar over October 6 to October 10, 1997. The data comes from one of the leading electronic FX transaction platforms, Reuters D2000-2, which is updated to D3000-2 now. The original dataset contains two data files. One dataset records the real-time quotes for the exchange rate Deutsche mark against US dollar, which includes the time stamp, the best bid price, and the best ask price at a particular time. The other dataset records the realtime trade, which includes the time stamp, the trade quantity, the trade direction, and the trade price. The vast majority of transactions on Deutsche mark/US dollar take place between 6 am and 6 pm, Monday to Friday although foreign exchange transaction takes place on the Reuters system D2000-2 24 hours a day and 7 days a week. The empirical analyses in 


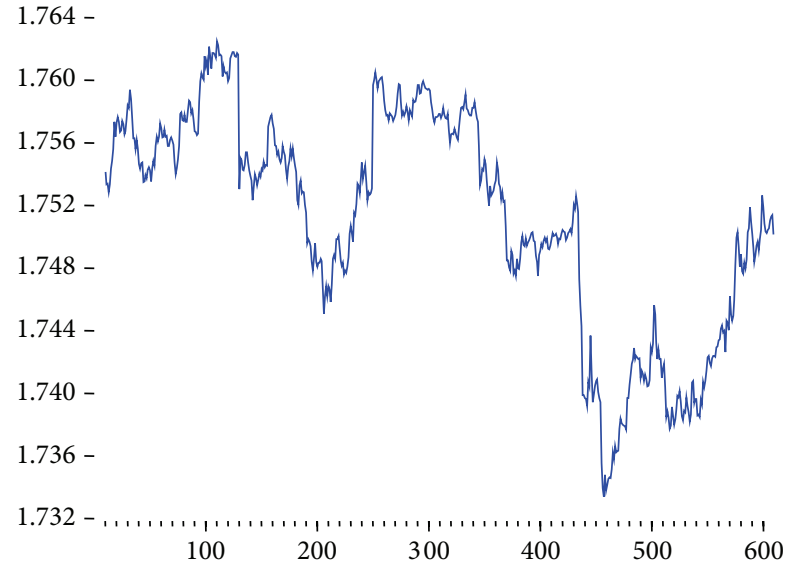

FIGURE 1: Exchange rate Deutsche mark/US dollar (5-minute frequency).

the following sections are based on the subsample, which includes a vast number of trades and provides us with a considerable power to test the impact of order flow on the exchange rate.

The dataset has distinguishing features which are worth mentioning. The first noticeable feature is that the dataset contains the real transaction prices instead of the indicative quotes which are often used in the relevant applied studies. The midquote is a typical proxy for the trade price. However, one fact is that the midquote may not represent a true state of the market especially when the market is thin or the market is one-sided (i.e., strong buying pressure or selling pressure). Thus, the midquote may not be representative. Although our sample span is relatively short, which is five days from October 6 to October 10, 1997, our attention is focused on the association between the exchange rate return and order flow at extra high frequency that makes the time span of the sample long enough to our analysis. Figure 1 shows the exchange rate dynamics at 5-minute frequency. Another feature of the dataset is that it contains the exact transaction values for each trade instead of the number of the transactions which is often adopted in the relevant literatures; see, for example, Evans and Lyons [9]. Finally, with the trade direction indicator (i.e., buying or selling) and the corresponding contemporaneous transaction value, we can calculate the total transaction value and order flow for each individual period.

In our empirical analysis, we adopt two versions of measurements for order flow. According to FX microstructure theories, when the trade direction is positive it indicates that the actual trade is initiated by buyer, the trade is termed as the buyer-initiated trade. On the contrary, when the trade direction is negative it indicates that the real trade is initiated by seller, the trade is termed as the seller-initiated trade. Order flow $x_{t}$ at time $t$ is defined as the net value between buyer-initiated trades $B_{t}$ and the seller-initiated trades $S_{t}$, which is calculated by the following formula:

$$
x_{t}=S_{t}-B_{t}
$$

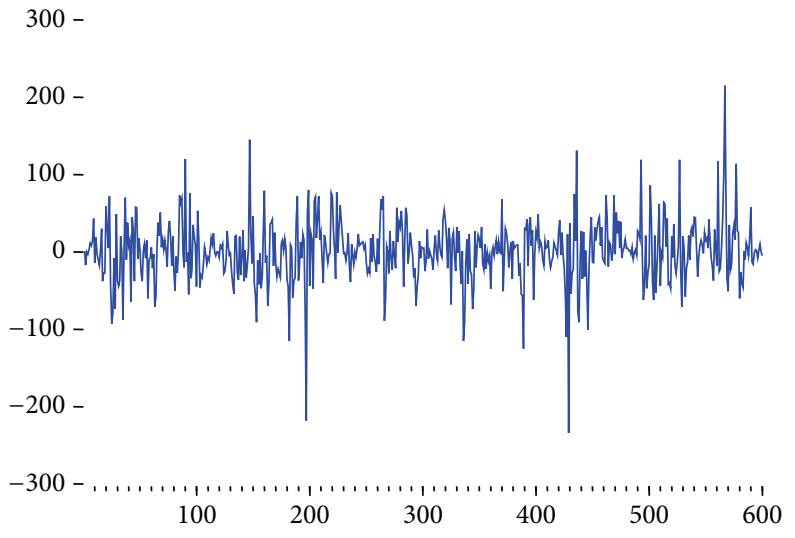

Figure 2: Order flow (5-minute frequency).

We demonstrate order flow $x_{t}$ in Figure 2, which graphically shows that order flow is a stationary $\mathrm{I}(0)$ process. Alternatively, we adopt another measurement for order flow, advocated by Ito and Hashimoto [6]. The measurement defines order flow as the ratio of the net trade pressure $\left(S_{t}-B_{t}\right)$ to the corresponding contemporaneous total trade quantity $Q_{t}$ which is equal to the sum of the two-sided trades, $\left(S_{t}+B_{t}\right)$. We term this order flow as order flow ratio, $x$ Ratio $_{t} . x$ Ratio $_{t}$ is calculated by the following formula:

$$
x \operatorname{Ratio}_{t}=\frac{\left(S_{t}-B_{t}\right)}{\left(S_{t}+B_{t}\right)} .
$$

Why we introduce this measurement for order flow? The intuition behind this measure is the fact that the whole market activities vary from time to time. The ratio $x \mathrm{Ratio}_{t} \mathrm{can}$ measure the degree of market activeness. We demonstrate the principle in the following typical artificial example (Ito and Hashimoto [6]): when the market is active during a particular time period, we can have a buyer-initiated trade $B_{t}=1000$ and a seller-initiated trade $S_{t}=990$. But we can only have a buyer-initiated trade $B_{t}=100$ and a seller-initiated trade $S_{t}=90$ when the market is calm. In the two scenarios, we have the same quantity of order flow $x_{t}$, which is 10 . However, order flow ratio $x$ Ratio $_{t}$ is, respectively, 0.001 and 0.01 in the two cases. This example indicates the different characteristics between these two different measurements. Figure 3 demonstrates order flow ratio $x$ Ratio $_{t}$ at 5-minute frequency, which is apparently different from the plot in Figure 2.

To examine the association between exchange rates and order flow at high-frequency and check the persistence of the relationship, we use 5-minute frequency as the interval basis and aggregate order flow to order flow 10-minute, 15minute, 20-minute, 25-minute, and 30-minute frequencies. We construct the change in the log of the spot exchange rate $(\mathrm{DM} / \$$ times 100000$)$ as the exchange rate return $\Delta p_{t}$. The interdealer order flow $x_{t}$ is measured contemporaneously with the exchange rate return $\Delta p_{t}$. Tables 1 and 2 show, respectively, the descriptive statistics for the two measurements of order flow at various frequencies. 


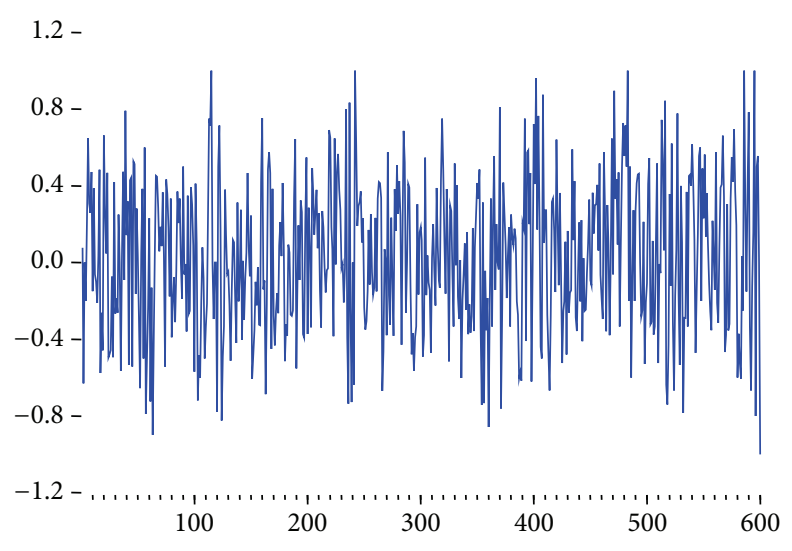

FIgURE 3: Order flow ratio (5-minute frequency).

\section{Analysis Concerns and Arrangements}

Our primary goal is to examine the association between exchange rates and contemporaneous order flow and investigate the predictability of order flow on the future exchange rate. Before the formal implementation, we discuss several issues involved in the actual analysis. The first concern is the possible endogeneity of order flow in the actual association between exchange rates and order flow, which is usually due to the simultaneity between foreign exchange trading and quoting. Another concern is the possible nonlinearity involved in the association between exchange rates and order flow.

4.1. Endogeneity. Relevant studies demonstrate that order flow carries information and has permanent effect on exchange rates. Meanwhile, it is necessary to focus on the joint determination between exchange rates and order flow, which is mostly of concern in the feedback trading. Feedback trading means that the foreign exchange trading determines the movements of exchange rates meanwhile exchange rate levels impact the foreign exchange trading. Relevant empirical studies usually accept the assumption that trade (order flow) precedes the quotes (trading prices). Under this implication, the VAR structure of Hasbrouck [10] has been frequently used in exchange rate modelling, such as Payne [8] and Killeen et al. [3], to assess how informative order flow is. These studies include the contemporaneous order flow in the exchange rate return equation while they exclude the contemporaneous exchange rate return from the trade (order flow) equation. The nonstandard VAR approach logically removes the endogeneity issue from the simultaneity between the two series. However, there are arguments, such as Lyons [1] and Daníelsson and Love [11], that there is contemporaneous feedback trading between trades and quotes.

To check the simultaneity between the exchange rate and order flow, we adopt the 5-minute interval data as the analysis basis. The intuition behind this choice is that when the tick-by-tick data is aggregated into low-frequency data the feedback trade effect can be identified easily. Love and Payne [12] address that the notation of feedback trading which

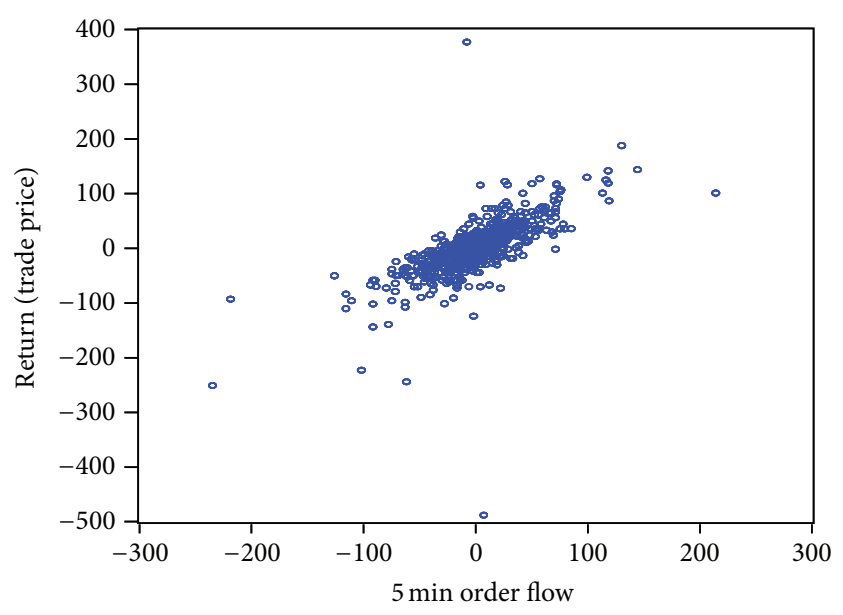

FIGURE 4: DM/USD exchange rate return and order flow (5-minute frequency).

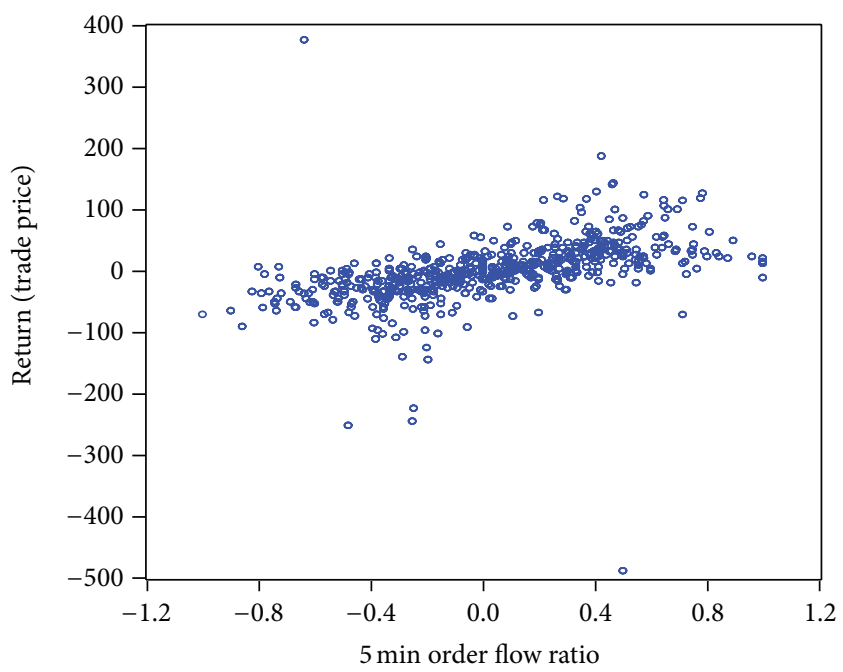

FIGURE 5: DM/USD exchange rate return and order flow ratio (5minute frequency).

allows order flow to respond to price movements at frequency of less than one minute is somewhat dubious. Daníelsson and Love [11], using nonstandard VAR specification and instrumental variable (IV) method, find that if the data are sampled at anything other than at the highest frequency then any feedback trading may well appear contemporaneous and the trading in period $t$ depends on the asset return in that interval.

Mapping the feedback trading to our single-direction equation estimation, we are concerned with the endogeneity of order flow in the single-direction association that we have to identify whether order flow is endogenous in our specification. On the presence of the endogeneity coming from the jointly simultaneous determination between the exchange rate and the contemporaneous order flow, we should use instrument techniques to handle the endogeneity issue in the regression. Compared with OLS estimation, 
instrument variable estimation (IV) and the generalized methods of moments (GMM) estimation are for the consistency at presence of endogeneity. However, results from IV and GMM hold cost of the loss of efficiency if there is no endogeneity involved in the specified equation. We firstly regress the exchange rate return on order flow at 5-minute and 30-minute frequencies and check the correlation between order flow and the regression residuals. The results reject the hypothesis that there is correlation between order flow and the residual term of the equation.

4.2. Nonlinearity. The majority of the empirical studies we discussed above confirm the positive association between exchange rates and order flow in a linear specification. Meanwhile, there is possible nonlinearity involved in the relationship, which matters significantly in our short-span sample. Payne [8] identifies nonlinearity in the association and then he creates a nonlinear VAR in his empirical analysis. Evans and Lyons [13] directly use nonparametric method in their empirical analysis, which avoids the drawbacks of the direct parametric linear specification. We demonstrate the scatter-plots between the exchange rate return and order flow at two frequencies (5-minute and 30-minute) in Figures $4,5,6$, and 7 . These figures indicate clearly a systematic, approximately linear positive relation between exchange rates and order flow at both 5-minute and 30-minute frequencies. We conclude that the relationship is clearly not the result of a small number of outliers and no nonlinearity is evident in the association.

Given that we have justified the linear association between exchange rates and order flow at both frequencies, we can proceed to estimate the specific association. In the following subsections, we introduce the arrangement for estimating the contemporaneous relationship between exchange rate return and the contemporaneous order flow and the arrangement for investigating the prediction ability of order flow on the future exchange rate return at high frequency.

4.3. Contemporaneous Price Impact. The positive order flow represents net buying pressure and the negative order flow represents net selling pressure. Thus, we expect that buying pressure raises the transaction prices and selling pressure lowers the transaction prices. In the studies we discussed in previous sections the return equation includes both the contemporaneous and lagged order flows as the explanatory determinants, such as those of Evans and Lyons [2] and Payne [8]. Slightly different, at this stage we only include the contemporaneous order flow in the determination regression and examine the contemporaneous association between the exchange rate movement and order flow at various frequencies $(5,10,15,20,25$, and 30 minutes). According to the two different measurements of order flow we discussed in the data description section, our practical contemporaneous regression equations are specified as follows. For order flow, we have

$$
\Delta p_{t, h}=c+\alpha x_{t, h}+\varepsilon_{t, h}
$$

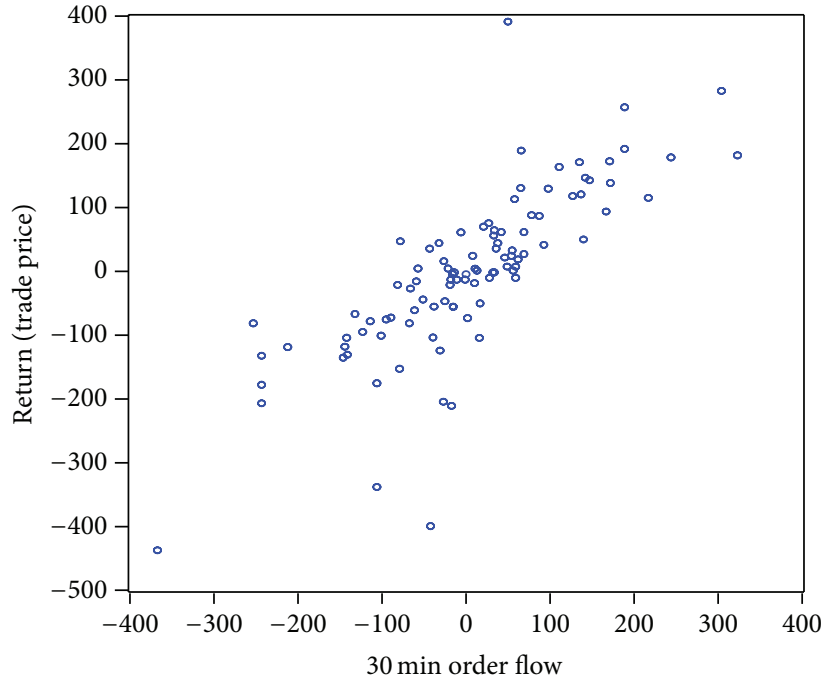

FIGURE 6: DM/USD exchange rate return and order flow (30-minute frequency).

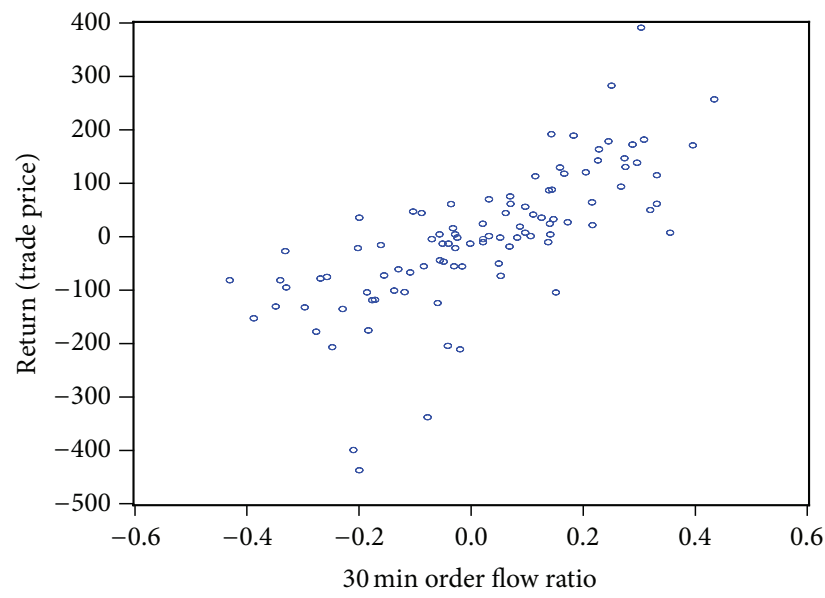

FIGURE 7: DM/USD exchange rate return and order flow ratio (30minute frequency).

and for order flow ratio, we have

$$
\Delta p_{t, h}=c+\alpha * x \text { Ratio }_{t, h}+\varepsilon_{t, h}
$$

where $\Delta p_{t, h}$ denotes the exchange rate return over a horizon $h . x_{t, h}$ and $x$ Ratio $_{t, h}$ represent, respectively, the two different measurements of order flow over the same horizon. $\varepsilon_{t, h}$ is the error term. The horizon $h$ is initially set up at 5-minute frequency to calculate order flow. We aggregate the 5-minute order flow to order flow at 10-minute, 15-minute, 20-minute, 25-minute, and 30-minute frequencies.

4.4. Future Price Prediction. To directly investigate the prediction power of order flow on the future exchange rate return, we only include the lagged exchange rate returns and lagged order flow in the return equation. Corresponding to 
TABLE 1: Order flow descriptive statistics at different horizons.

\begin{tabular}{lcccccc}
\hline & 5 minutes & 10 minutes & 15 minutes & 20 minutes & 25 minutes & 30 minutes \\
\hline Mean & 0.881667 & 1.763333 & 2.645000 & 3.526667 & 4.408333 & 5.290000 \\
Median & 1.500000 & 5.000000 & 8.000000 & 4.000000 & 1.000000 & 6.000000 \\
Maximum & 215.0000 & 269.0000 & 356.0000 & 410.0000 & 283.0000 & 324.0000 \\
Minimum & -234.0000 & -197.0000 & -321.0000 & -279.0000 & -345.0000 & -366.0000 \\
Std. dev. & 39.64055 & 58.94865 & 76.67211 & 90.37102 & 102.3269 & 115.9329 \\
\hline
\end{tabular}

This table reports some summary statistics for order flow, measured in millions of dollars, at 5-minute frequency, and aggregated to 10-minute, 15-minute, 20minute, 25-minute, and 30-minute frequencies.

TABLE 2: Order flow ratio descriptive statistics at different horizons.

\begin{tabular}{|c|c|c|c|c|c|c|}
\hline & 5 minutes & 10 minutes & 15 minutes & 20 minutes & 25 minutes & 30 minutes \\
\hline Mean & 0.031845 & 0.027866 & 0.026526 & 0.029278 & 0.025767 & 0.020082 \\
\hline Median & 0.032796 & 0.043438 & 0.043140 & 0.015080 & 0.001379 & 0.023331 \\
\hline Maximum & 1.000000 & 0.736842 & 0.709924 & 0.684211 & 0.531429 & 0.435780 \\
\hline Minimum & -1.000000 & -0.729167 & -0.725191 & -0.531469 & -0.517647 & -0.428571 \\
\hline Std. dev. & 0.392208 & 0.304738 & 0.270706 & 0.236041 & 0.219407 & 0.195233 \\
\hline
\end{tabular}

This table reports some summary statistics for order flow ratio measured at 5-minute frequency and aggregated to 10-minute, 15-minute, 20-minute, 25-minute, and 30-minute frequencies.

the two contemporaneous determination equations above, we specify the two prediction associations as follows:

$$
\begin{gathered}
\Delta p_{t}=\beta_{0}+\sum_{i=1}^{m} \gamma_{i} \Delta p_{t-i}+\sum_{i}^{m} \delta_{i} x_{t-i}+\varepsilon_{t} \\
\Delta p_{t}=\beta_{0}+\sum_{i=1}^{m} \gamma_{i} \Delta p_{t-i}+\sum_{i}^{m} \delta_{i} x \text { Ratio }_{t-i}+\varepsilon_{t}
\end{gathered}
$$

where $\Delta p_{t}$ denotes the exchange rate return from period $t-1$ to $t . x_{t-i}$ is the lagged order flow. We regress the exchange rate return on the lagged order flow and lagged exchange rate return at 5 minutes and 10 minutes, respectively. We choose 5 as the maximum lag $m$ for both the exchange rate return and order flow. With the maximum lag 5, we aim to test whether the predictability of order flow can be ahead of halfhour when the data is measured at 5-minute frequency and one-hour when the data is measured at 10-minute frequency. Considering the discontinuity of the data (we only focus on period from 06:00 am to 06:00 pm in our contemporaneous analysis), we separately examine the prediction power of order flow in the Granger-causality regressions, based on the data from the five different days.

\section{Empirical Data Analysis}

During the test whether order flow is endogenous in the contemporaneous regression, we fail to accept the hypothesis that the order flow is correlated with the regression residual term. Moreover, this conclusion is valid for the two measurements of order flow at all the chosen frequencies. Thus, we accept the validity of the assumption that trading precedes the quoting. For relevant studies, see those of Evans and Lyons [2], Berger et al. [5], and Ito and Hashimoto [6].
5.1. Contemporaneous Price Impact. Before the actual estimation, we firstly investigate whether the two measurements of order flow in our study, order flow and order flow ratio, are stationary processes. Killeen et al. [3] find a longrun cointegration relation between exchange rate levels and cumulated order flow. In our relative short sample, we expect that the two measures of order flow are stationary processes, which are shown in Figures 2 and 3. Table 3 reports the unit root test results for the two measurements of order flow at 5-minute and 30-minute frequencies. The tests confirm that order flow and order flow ratio are consistently $\mathrm{I}(0)$ series at 10-minute, 15-minute, 20-minute, and 25-minute frequencies.

According to (4) and (5), we use OLS to implement the estimation of the contemporaneous association. Tables 4 and 5 report the estimation results for the impact of order flow on the contemporaneous exchange rate return. For the two measurements of order flow, the results suggest that all the coefficient estimates are statistically significant and correctly signed at all frequencies. The magnitudes of the coefficients on order flow imply that the contemporaneous impact of order flow is significant. The determination coefficient $R$ squares ranges from 47 percent to 61 percent for the case of order flow and varies from 26 percent to 52 percent for the case of order flow ratio. These results are consistent with the study of Evans and Lyons [9]. We also separately regress the exchange rate return on order flow for the five days of our sample and the estimates are significantly close to those we report here.

Our coefficient estimates reported in Tables 4 and 5 are consistent with our theoretical hypothesis. Meanwhile, they are different in magnitude from the estimates of Evans and Lyons [9]. We think one possible reason could be because our estimate is concerned the association between the exchange rate return with order flow at a higher frequency, that is, 5minute and 10-minute frequencies, and so forth. However, 
TABLE 3: Tests for a unit root in the data (order flow and order flow ratio).

\begin{tabular}{|c|c|c|c|c|}
\hline Horizon, $h$ & Level $\tau_{\mu}$ & 1st difference $\tau_{\mu}$ & Level $\tau_{\tau}$ & 1st difference $\tau_{\tau}$ \\
\hline \multicolumn{5}{|l|}{ 5-minute } \\
\hline$x_{t}$ & -20.60183 & $-13.58463(9)$ & -20.65302 & $-13.57312(9)$ \\
\hline$x$ Ratio $_{t}$ & -21.05210 & $-15.15247(7)$ & -21.15086 & $-15.13972(7)$ \\
\hline \multicolumn{5}{|l|}{ 30-minute } \\
\hline$x_{t}$ & -10.55059 & $-12.63489(1)$ & -10.68869 & $-12.56727(1)$ \\
\hline$x$ Ratio $_{t}$ & -10.69478 & $-10.59656(2)$ & -11.26808 & $-10.53929(2)$ \\
\hline
\end{tabular}

The symbols $x_{t}$ and $x$ Ratio $_{t}$ denote, respectively, order flow and order flow ratio (see the text for data source and exact definitions). The reported numbers in the columns are the Dickey-Fuller statistics for the null hypothesis that the sum of the coefficients in the autoregressive representation of the variables sum to unity. $\tau_{\mu}$ is the test statistic allowing for only constant in mean and $\tau_{\tau}$ is the test statistic allowing for both constant and trend in mean. The numbers in parenthesis after these statistics indicate the lag length used in the autoregression, determined by the Schwarz information criterion. For the test statistics, the null hypothesis is that the series in question is I(1).

TABLE 4: Estimates of (4) at different horizons.

\begin{tabular}{lcc}
\hline Horizon, $h$ & Beta-hat (OF) & $R$-squared \\
\hline 5-minute & $0.9083667(0.0389624)$ & 0.4757 \\
10 -minute & $0.9149569(0.0491146)$ & 0.5388 \\
$15-$ minute & $0.9182686(0.0572092)$ & 0.5667 \\
20 -minute & $0.9525129(0.0640856)$ & 0.6004 \\
25-minute & $0.8624387(0.0727042)$ & 0.5421 \\
30-minute & $0.8703092(0.0695521)$ & 0.6135 \\
\hline
\end{tabular}

The net order flow (OF) represents the net value of buyer-initiated trade minus the seller-initiated trade, measured in millions of dollars; numbers in the parenthesis are the standard errors for the corresponding coefficient estimates.

Evans and Lyons's analysis is based on the aggregated daily data. We can observe in Tables 4 and 5 that when the data frequency gets lower the impact of order flow gets larger. We also observe the sensitivities of the approaches to measure order flow. The exchange rate return is more sensitive to order flow ratio than order flow.

5.2. Prediction Analysis. To investigate the prediction of lagged order flow on future exchange rate return, we estimate (6) and (7) with OLS. Tables 6 and 7 separately report, for the five days, the estimation results for the regression of the exchange rate return on the lagged exchange rate return and lagged order flow. Table 6 is for the case that net order flow is taken as the explanatory variable and Table 7 is for the case that order flow ratio is taken as the explanatory variable. Generally, all the results indicate weak prediction power of order flow on the future exchange rate return. In the case of order flow at five-minute frequency, reported in Table 6, except in day 3 and day 5 , the coefficients on the first lagged order flow are not significant and wrongly signed. Other coefficients on lagged order flow during the five days are also not statistically significant and wrongly signed. In the case of order flow ratio, reported in Table 7, the coefficients are not statistically significant even positively signed. Similarly, at 10-minute frequency, reported in Tables 8 and 9, only in day 3 the coefficients on the first lagged order flow and order flow ratio appear to be correctly sighed and significant. The $F$-statistics for the regressions show lagged order flow are not jointly different from zero though in some cases the adjusted $R$-squares are not essentially zero.
Overall, the estimation results reported in Tables 6, 7, 8, and 9 suggest that lagged order flow has weak predictability of the future exchange rate return. For the majority the impact is not beyond 10 minutes. This result is consistent with those of Berger et al. [5] and Ito and Hashimoto [6]. The results also appear to confirm the conventional wisdom in the academic literatures that the exchange rate follows a random walk process at frequency less than annual such as daily, weekly, or even monthly.

5.3. Market Efficiency. Due to the significant impact of order flow on the contemporaneous exchange rate return and weak prediction of lagged order flow on the future exchange rate return, we investigate the serial dependence involved in order flow. We investigate the autocorrelation of order flow at 5 minutes and 10 minutes, which are shown in Figures 8, 9, 10, and 11. The figures indicate that within 95 percent confidence intervals the autocorrelation is centered at zero, shown as shaded areas. Within the entire sample span, the highest level (positive) of autocorrelations is only found at lag 1 at 5 -minute frequency. The weak autocorrelation is consistent with the prediction analysis results that order flow has weak prediction on exchange rates at 5-minute frequency.

For the data at 10-minute frequency, the autocorrelation of order flow is demonstrated in Figures 10 and 11. According to the figures, apparently, we cannot find strong autocorrelations involved, even at the first lag. Thus, there is no significant impact on the exchange rate return beyond 10 minutes.

The weak autocorrelation in order flow, demonstrated in Figures 8 to 11, indicates how poorly informative a dealer's 
TABLE 5: Estimates of (5) at different horizons.

\begin{tabular}{lcc}
\hline Horizon, $h$ & Beta-hat (OFR) & $R$-squared \\
\hline 5-minute & $0.6821226(0.04672573)$ & 0.2618 \\
10-minute & $1.363381(0.1159284)$ & 0.3177 \\
15-minute & $2.049136(0.1991693)$ & 0.3495 \\
20-minute & $3.133242(0.2923226)$ & 0.4349 \\
25-minute & $3.403084(0.3952186)$ & 0.3827 \\
30-minute & $4.765898(0.4607529)$ & 0.5196 \\
\hline
\end{tabular}

The net order flow ratio (OFR) represents the ratio of net order flow to the corresponding contemporaneous trade quantity over the same period, measured in millions of dollars; numbers in the parenthesis are the standard errors for the corresponding coefficient estimates.

TABLE 6: Granger's causality estimation of (6) (5-minute frequency).

\begin{tabular}{|c|c|c|c|c|c|}
\hline & Day 1 & Day 2 & Day 3 & Day 4 & Day 5 \\
\hline \multicolumn{6}{|l|}{ Order flow } \\
\hline $\mathrm{L} 1$ & $\begin{array}{c}-0.118071 \\
(0.19506)\end{array}$ & $\begin{array}{c}-0.137330 \\
(0.16762)\end{array}$ & $\begin{array}{l}0.218996 \\
(0.16716)\end{array}$ & $\begin{array}{c}-0.220818 \\
(0.23302)\end{array}$ & $\begin{array}{c}0.293388 \\
(0.20688)\end{array}$ \\
\hline $\mathrm{L} 2$ & $\begin{array}{c}-0.120591 \\
(0.19228)\end{array}$ & $\begin{array}{c}-0.088450 \\
(0.16622)\end{array}$ & $\begin{array}{c}-0.060422 \\
(0.16300)\end{array}$ & $\begin{array}{c}-0.013327 \\
(0.23357)\end{array}$ & $\begin{array}{c}-0.299061 \\
(0.20852)\end{array}$ \\
\hline L3 & $\begin{array}{l}0.108081 \\
(0.19130)\end{array}$ & $\begin{array}{c}-0.172152 \\
(0.16703)\end{array}$ & $\begin{array}{l}0.268007 \\
(0.15693)\end{array}$ & $\begin{array}{c}-0.447154 \\
(0.23714)\end{array}$ & $\begin{array}{c}-0.410111 \\
(0.20512)\end{array}$ \\
\hline $\mathrm{L} 4$ & $\begin{array}{c}-0.190258 \\
(0.18857)\end{array}$ & $\begin{array}{c}-0.311102 \\
(0.16644)\end{array}$ & $\begin{array}{c}-0.051263 \\
(0.15932)\end{array}$ & $\begin{array}{c}-0.014220 \\
(0.23410)\end{array}$ & $\begin{array}{l}0.235299 \\
(0.21190)\end{array}$ \\
\hline L5 & $\begin{array}{c}-0.022752 \\
(0.18485)\end{array}$ & $\begin{array}{c}0.270998 \\
(0.15131)\end{array}$ & $\begin{array}{c}-0.096563 \\
(0.15590)\end{array}$ & $\begin{array}{c}0.167554 \\
(0.23372)\end{array}$ & $\begin{array}{c}-0.269974 \\
(0.20186)\end{array}$ \\
\hline \multicolumn{6}{|c|}{ Exchange rate return } \\
\hline $\mathrm{L} 1$ & $\begin{array}{l}0.150455 \\
(0.17953)\end{array}$ & $\begin{array}{l}0.256772 \\
(0.16881)\end{array}$ & $\begin{array}{c}0.023109 \\
(0.17056)\end{array}$ & $\begin{array}{c}0.257228 \\
(0.17044)\end{array}$ & $\begin{array}{c}-0.135055 \\
(0.17139)\end{array}$ \\
\hline $\mathrm{L} 2$ & $\begin{array}{l}0.064654 \\
(0.17867)\end{array}$ & $\begin{array}{c}-0.043441 \\
(0.16814)\end{array}$ & $\begin{array}{c}-0.086769 \\
(0.16403)\end{array}$ & $\begin{array}{l}0.148246 \\
(0.17029)\end{array}$ & $\begin{array}{c}0.031216 \\
(0.17199)\end{array}$ \\
\hline $\mathrm{L} 3$ & $\begin{array}{c}-0.015274 \\
(0.17925)\end{array}$ & $\begin{array}{c}0.217579 \\
(0.16979)\end{array}$ & $\begin{array}{c}-0.239797 \\
(0.16118)\end{array}$ & $\begin{array}{l}0.330404 \\
(0.17486)\end{array}$ & $\begin{array}{l}0.255290 \\
(0.16949)\end{array}$ \\
\hline $\mathrm{L} 4$ & $\begin{array}{c}0.172611 \\
(0.17717)\end{array}$ & $\begin{array}{l}0.385293 \\
(0.16870)\end{array}$ & $\begin{array}{c}-0.093093 \\
(0.16256)\end{array}$ & $\begin{array}{l}0.106227 \\
(0.17636)\end{array}$ & $\begin{array}{c}-0.215438 \\
(0.17468)\end{array}$ \\
\hline L5 & $\begin{array}{c}-0.169169 \\
(0.17404)\end{array}$ & $\begin{array}{c}-0.245181 \\
(0.15871)\end{array}$ & $\begin{array}{c}-0.055984 \\
(0.16353)\end{array}$ & $\begin{array}{c}-0.232155 \\
(0.17743)\end{array}$ & $\begin{array}{c}0.121239 \\
(0.17028)\end{array}$ \\
\hline Constant & $\begin{array}{c}2.816570 \\
(4.10656) \\
\end{array}$ & $\begin{array}{c}-0.516888 \\
(4.00396) \\
\end{array}$ & $\begin{array}{c}-5.881906 \\
(3.26599) \\
\end{array}$ & $\begin{array}{c}-1.067474 \\
(5.48496) \\
\end{array}$ & $\begin{array}{c}7.343517 \\
(5.01448) \\
\end{array}$ \\
\hline Adjusted $R$-sq & -0.013954 & 0.047594 & 0.020127 & 0.030615 & 0.038009 \\
\hline$F$-statistic & 0.844486 & 1.564692 & 1.232112 & 1.356878 & 1.446467 \\
\hline$P$ value & 0.5872 & 0.1277 & 0.2796 & 0.2110 & 0.1707 \\
\hline
\end{tabular}

This table reports the results of the regressions of the exchange rate return at 5-minute frequency on five lags of order flow and five lags of exchange rate returns over the five days in the sample. Standard errors are reported in the parentheses below the coefficient estimates. The $F$-statistics and $P$ value are from the $F$ tests, which indicate lagged order flow coefficients are not jointly different from zero.

trading information is to other dealers in the FX market. Consistent with this fact, the portfolio-shift model of Evans and Lyons [2] truly indicates that the initial order flow in the first two-round trades does not suggest much actual market information to all the involved dealers who always attempt to avoid revealing their own inventory positions and trading motivations. Specifically, the price (exchange rate) in the portfolio-shift model is assumed purely to be determined by the market makers existing in the FX market. Meanwhile, in the interdealer market these market makers are various financial institutions that always attempt to protect themselves and make speculation with informed information. Thus, the information based on the posttrade order flow cannot reflect all information of the prices.

5.4. Daily Forecasting of Order Flow on Exchange Rates. Additionally, we examine the predictability of order flow on the future exchange return with the daily frequency data used by Evans and Lyons [2]. Table 10 reports the Grangercausality regression results of Deutsche mark/US dollar and Japanese yen/US dollar on the lagged exchange rate returns 
TABLE 7: Granger's causality estimation of (7) (5-minute frequency).

\begin{tabular}{|c|c|c|c|c|c|}
\hline & Day 1 & Day 2 & Day 3 & Day 4 & Day 5 \\
\hline \multicolumn{6}{|l|}{ Order flow ratio } \\
\hline $\mathrm{L} 1$ & $\begin{array}{l}0.0127747 \\
(1.35864)\end{array}$ & $\begin{array}{c}-0.1026879 \\
(1.64811)\end{array}$ & $\begin{array}{c}1.431332 \\
(1.32566)\end{array}$ & $\begin{array}{l}0.9731951 \\
(1.74083)\end{array}$ & $\begin{array}{l}1.370567 \\
(1.59191)\end{array}$ \\
\hline $\mathrm{L} 2$ & $\begin{array}{c}0.1546971 \\
(1.35789)\end{array}$ & $\begin{array}{c}-0.0067625 \\
(1.64395)\end{array}$ & $\begin{array}{l}1.739592 \\
(1.28954)\end{array}$ & $\begin{array}{c}-0.8501948 \\
(1.76384)\end{array}$ & $\begin{array}{c}0.2341238 \\
(1.57967)\end{array}$ \\
\hline L3 & $\begin{array}{l}1.132090 \\
(1.36198)\end{array}$ & $\begin{array}{r}-1.984280 \\
(1.62947)\end{array}$ & $\begin{array}{l}0.9612191 \\
(1.26949)\end{array}$ & $\begin{array}{c}-1.539022 \\
(1.77396)\end{array}$ & $\begin{array}{c}-1.961865 \\
(1.60199)\end{array}$ \\
\hline $\mathrm{L} 4$ & $\begin{array}{c}-1.763775 \\
(1.35909)\end{array}$ & $\begin{array}{c}-2.677360 \\
(1.68247)\end{array}$ & $\begin{array}{c}0.4618692 \\
(1.26981)\end{array}$ & $\begin{array}{c}0.8257213 \\
(1.76976)\end{array}$ & $\begin{array}{c}-0.2814629 \\
(1.53728)\end{array}$ \\
\hline L5 & $\begin{array}{c}-0.0692894 \\
(1.35542)\end{array}$ & $\begin{array}{c}3.401814 \\
(1.69208)\end{array}$ & $\begin{array}{c}-2.043698 \\
(1.22580)\end{array}$ & $\begin{array}{l}1.084196 \\
(1.78272)\end{array}$ & $\begin{array}{c}-1.630415 \\
(1.56783)\end{array}$ \\
\hline \multicolumn{6}{|c|}{ Exchange rate return } \\
\hline $\mathrm{L} 1$ & $\begin{array}{l}0.066245 \\
(0.13549)\end{array}$ & $\begin{array}{c}0.151886 \\
(0.13252)\end{array}$ & $\begin{array}{l}0.058555 \\
(0.14190)\end{array}$ & $\begin{array}{l}0.088925 \\
(0.11628)\end{array}$ & $\begin{array}{c}-0.031734 \\
(0.13489)\end{array}$ \\
\hline $\mathrm{L} 2$ & $\begin{array}{c}-0.055129 \\
(0.13503)\end{array}$ & $\begin{array}{c}-0.133859 \\
(0.13305)\end{array}$ & $\begin{array}{c}-0.219643 \\
(0.13753)\end{array}$ & $\begin{array}{l}0.188863 \\
(0.11694)\end{array}$ & $\begin{array}{c}-0.157064 \\
(0.13524)\end{array}$ \\
\hline L3 & $\begin{array}{c}-0.023257 \\
(0.13392)\end{array}$ & $\begin{array}{l}0.182826 \\
(0.13239)\end{array}$ & $\begin{array}{c}-0.101251 \\
(0.13789)\end{array}$ & $\begin{array}{c}0.111203 \\
(0.11765)\end{array}$ & $\begin{array}{l}0.071740 \\
(0.13608)\end{array}$ \\
\hline $\mathrm{L} 4$ & $\begin{array}{l}0.144834 \\
(0.13323)\end{array}$ & $\begin{array}{l}0.243417 \\
(0.13497)\end{array}$ & $\begin{array}{c}-0.123974 \\
(0.14026)\end{array}$ & $\begin{array}{l}0.019763 \\
(0.11721)\end{array}$ & $\begin{array}{c}-0.066863 \\
(0.13152)\end{array}$ \\
\hline L5 & $\begin{array}{c}-0.190439 \\
(0.13387)\end{array}$ & $\begin{array}{c}-0.274561 \\
(0.13508)\end{array}$ & $\begin{array}{c}-0.006818 \\
(0.13651)\end{array}$ & $\begin{array}{c}-0.166060 \\
(0.11667)\end{array}$ & $\begin{array}{c}0.037412 \\
(0.13267)\end{array}$ \\
\hline Constant & $\begin{array}{l}3.880461 \\
(3.89964)\end{array}$ & $\begin{array}{c}-0.495662 \\
(4.02191)\end{array}$ & $\begin{array}{c}-5.822364 \\
(3.36141) \\
\end{array}$ & $\begin{array}{c}-2.927650 \\
(6.20530) \\
\end{array}$ & $\begin{array}{l}6.910383 \\
(5.13380) \\
\end{array}$ \\
\hline Adjusted $R$-sq & -0.013033 & 0.045517 & 0.031465 & -0.008714 & -0.023858 \\
\hline$F$-statistic & 0.854623 & 1.538870 & 1.367102 & 0.902379 & 0.736689 \\
\hline$P$ value & 0.5778 & 0.1362 & 0.2060 & 0.5339 & 0.6884 \\
\hline
\end{tabular}

This table reports the results of the regressions of the exchange rate return at the 5-minute frequency on five lags of order flow and five lags of exchange rate returns over the five days in the sample. Standard errors are reported in the parentheses below the coefficient estimates. The $F$-statistics and $P$ value are from the $F$-tests, which indicate lagged order flow coefficients are not jointly different from zero.

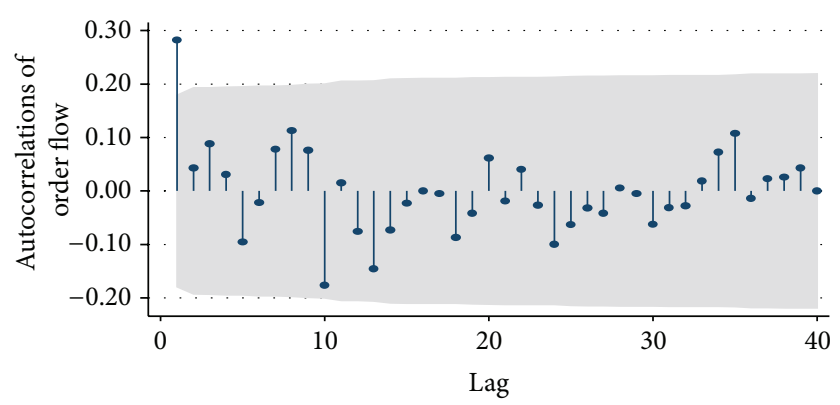

Bartlett's formula for MA(q) 95\% confidence bands

FIGURE 8: DM/USD order-flow autocorrelations (5-minute frequency). Shaded region denotes $95 \%$ confidence interval.

and lagged order flow at the daily frequency. The coefficients on the first lag of order flow are clearly positive but not statistically significant. The $F$-statistic and $P$ values indicate that the lagged order flow have no any predictive power on the future exchange rate return.

\section{Conclusions}

The microstructure theories suggest that order flow carries information and has permanent effects on exchange rates.

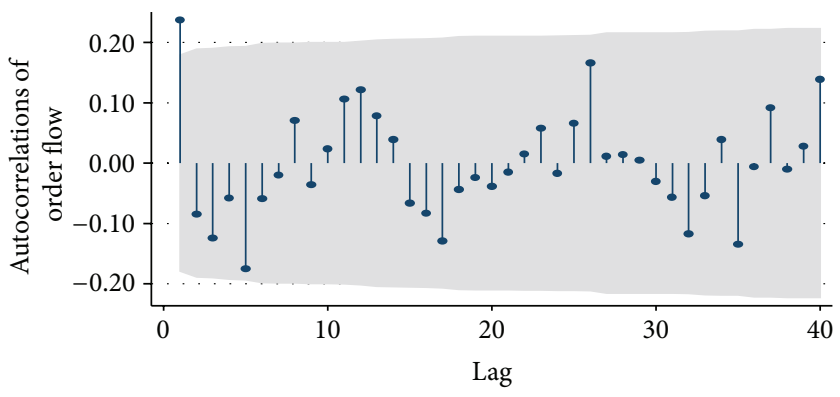

Bartlett's formula for MA(q) 95\% confidence bands

FIGURE 9: DM/USD order-flow-ratio autocorrelations (5-minute frequency). Shaded region denotes $95 \%$ confidence interval.

Using the transaction data on the exchange rate Deutsche mark/US dollar from one of the popular trading platforms, Reuters D2000-2, we examine the association between the exchange rate and order flow. Our analysis demonstrates that at intraday high-frequency order flow is a valuable determinant for the contemporaneous exchange rate returns. However, our experiments of the prediction of order flow on the future exchange rate indicate that the impact of order flow on the future exchange rate is quite vulnerable. Actually, the prediction on the future exchange rate return cannot go 
TABLE 8: Granger's causality estimation of (6) (10-minute frequency).

\begin{tabular}{|c|c|c|c|c|c|}
\hline & Day 1 & Day 2 & Day 3 & Day 4 & Day 5 \\
\hline \multicolumn{6}{|l|}{ Order flow } \\
\hline $\mathrm{Ll}$ & $\begin{array}{c}0.136435 \\
(0.34967)\end{array}$ & $\begin{array}{c}-0.089633 \\
(0.26324)\end{array}$ & $\begin{array}{l}0.526039 \\
(0.30753)\end{array}$ & $\begin{array}{c}-0.447771 \\
(0.36917)\end{array}$ & $\begin{array}{c}-0.446635 \\
(0.30271)\end{array}$ \\
\hline $\mathrm{L} 2$ & $\begin{array}{c}-0.308135 \\
(0.35084)\end{array}$ & $\begin{array}{c}-0.263654 \\
(0.26533)\end{array}$ & $\begin{array}{c}0.091605 \\
(0.28730)\end{array}$ & $\begin{array}{c}-0.401649 \\
(0.37418)\end{array}$ & $\begin{array}{c}-0.404804 \\
(0.28665)\end{array}$ \\
\hline L3 & $\begin{array}{l}0.688376 \\
(0.33985)\end{array}$ & $\begin{array}{l}0.209682 \\
(0.26306)\end{array}$ & $\begin{array}{c}-0.326159 \\
(0.29723)\end{array}$ & $\begin{array}{c}0.702109 \\
(0.37023)\end{array}$ & $\begin{array}{c}0.184541 \\
(0.28903)\end{array}$ \\
\hline $\mathrm{L} 4$ & $\begin{array}{c}-0.039688 \\
(0.33378)\end{array}$ & $\begin{array}{l}-0.481917 \\
(0.26637)\end{array}$ & $\begin{array}{c}0.235170 \\
(0.29056)\end{array}$ & $\begin{array}{l}0.272496 \\
(0.37699)\end{array}$ & $\begin{array}{r}-0.180359 \\
(0.30057)\end{array}$ \\
\hline L5 & $\begin{array}{l}0.035736 \\
(0.32321)\end{array}$ & $\begin{array}{c}0.214257 \\
(0.25365)\end{array}$ & $\begin{array}{c}-0.150053 \\
(0.26986)\end{array}$ & $\begin{array}{c}-0.086382 \\
(0.37463)\end{array}$ & $\begin{array}{c}0.153250 \\
(0.28587)\end{array}$ \\
\hline \multicolumn{6}{|c|}{ Exchange rate return } \\
\hline $\mathrm{L} 1$ & $\begin{array}{l}-0.191310 \\
(0.32897)\end{array}$ & $\begin{array}{c}0.231504 \\
(0.28081)\end{array}$ & $\begin{array}{c}-0.429302 \\
(0.30579)\end{array}$ & $\begin{array}{c}0.570028 \\
(0.26693)\end{array}$ & $\begin{array}{l}0.223603 \\
(0.29134)\end{array}$ \\
\hline $\mathrm{L} 2$ & $\begin{array}{l}0.196840 \\
(0.33985)\end{array}$ & $\begin{array}{c}0.287834 \\
(0.28982)\end{array}$ & $\begin{array}{c}-0.283998 \\
(0.30125)\end{array}$ & $\begin{array}{c}0.312146 \\
(0.27584)\end{array}$ & $\begin{array}{c}0.268175 \\
(0.26696)\end{array}$ \\
\hline L3 & $\begin{array}{c}-0.642743 \\
(0.32175)\end{array}$ & $\begin{array}{c}-0.265260 \\
(0.31380)\end{array}$ & $\begin{array}{c}0.201120 \\
(0.31266)\end{array}$ & $\begin{array}{c}-0.582852 \\
(0.26878)\end{array}$ & $\begin{array}{c}-0.262002 \\
(0.27343)\end{array}$ \\
\hline $\mathrm{L} 4$ & $\begin{array}{c}-0.036487 \\
(0.31441)\end{array}$ & $\begin{array}{c}0.392224 \\
(0.30960)\end{array}$ & $\begin{array}{c}-0.266103 \\
(0.29923)\end{array}$ & $\begin{array}{l}0.047003 \\
(0.27626)\end{array}$ & $\begin{array}{c}0.169784 \\
(0.28404)\end{array}$ \\
\hline L5 & $\begin{array}{l}-0.132261 \\
(0.30469)\end{array}$ & $\begin{array}{c}-0.000436 \\
(0.30732)\end{array}$ & $\begin{array}{c}0.043512 \\
(0.29192)\end{array}$ & $\begin{array}{c}-0.256454 \\
(0.27060)\end{array}$ & $\begin{array}{c}-0.308772 \\
(0.27394)\end{array}$ \\
\hline Constant & $\begin{array}{l}10.20020 \\
(10.1838)\end{array}$ & $\begin{array}{r}-0.338317 \\
(8.30204)\end{array}$ & $\begin{array}{c}-11.89428 \\
(8.39075)\end{array}$ & $\begin{array}{c}-6.790016 \\
(11.6759)\end{array}$ & $\begin{array}{l}16.56448 \\
(11.4245)\end{array}$ \\
\hline Adjusted $R$-sq & -0.040912 & -0.023319 & -0.066581 & 0.157572 & 0.028411 \\
\hline$F$-statistic & 0.791690 & 0.879226 & 0.669151 & 1.991340 & 1.154979 \\
\hline$P$ value & 0.6368 & 0.5592 & 0.7462 & 0.0583 & 0.3465 \\
\hline
\end{tabular}

This table reports the results of the regressions of the exchange rate return at the 10-minute frequency on five lags of order flow and five lags of exchange rate returns over the five days in the sample. Standard errors are reported in the parentheses below the coefficient estimates. The $F$-statistics and $P$ value are from the $F$-tests, which indicate lagged order flow coefficients are not jointly different from zero.

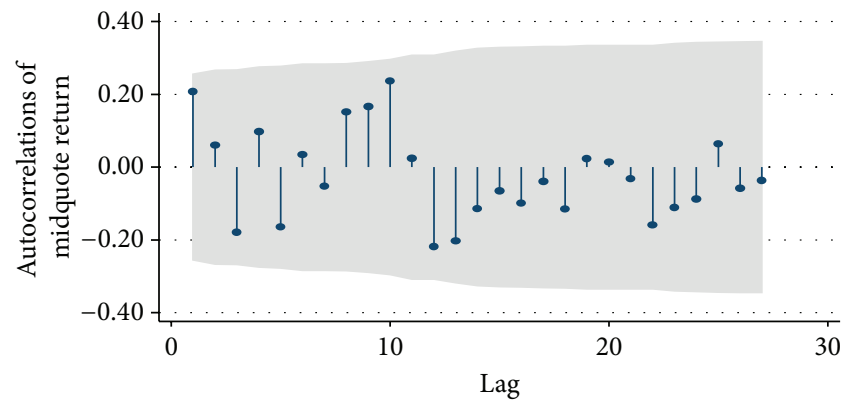

Bartlett's formula for MA(q) $95 \%$ confidence bands

FIGURE 10: DM/USD order-flow autocorrelations (10-minute frequency). Shaded region denotes $95 \%$ confidence interval.

beyond ten minutes. In the single equation analysis, we also investigate the possible reverse causality from the exchange rate return to order flow, which is termed as the feedback trading. However, our empirical analysis shows that order flow cannot be an endogenous variable in the contemporaneous determination relationship. We also investigate the historical dependence between sequential order flows, but we find the weak link between two close foreign exchange trades.

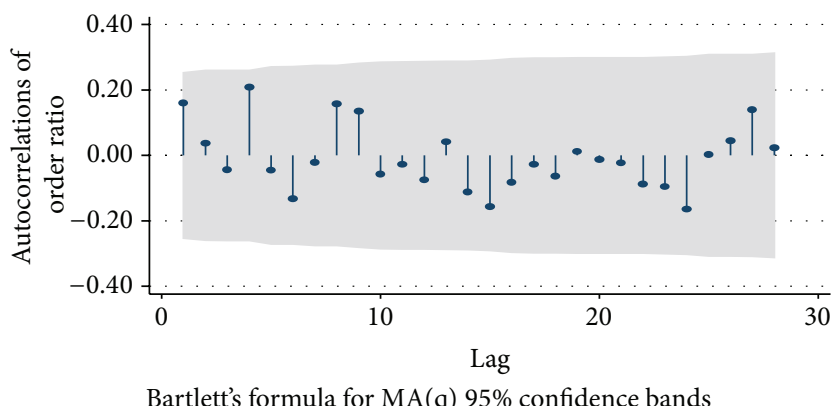

FIGURE 11: DM/USD order-flow-ratio autocorrelations (5-minute frequency). Shaded region denotes $95 \%$ confidence interval.

Market participants in the interdealer FX market always attempt to make profits with informed information. This feature determines that these individual market participants always attempt to be invisible to others. Thus, in the sequential foreign exchange trades, these dealers' positions are not easy to be used by others as the basis to judge the future foreign exchange rate movement direction. It is difficult to use order flow to predict the future exchange rate return, which 
TABLE 9: Granger's causality estimation of (7) (10-minute frequency).

\begin{tabular}{|c|c|c|c|c|c|}
\hline & Day 1 & Day 2 & Day 3 & Day 4 & Day 5 \\
\hline \multicolumn{6}{|l|}{ Order flow ratio } \\
\hline $\mathrm{L} 1$ & $\begin{array}{l}1.452997 \\
(4.18435)\end{array}$ & $\begin{array}{l}-7.161375 \\
(5.87120)\end{array}$ & $\begin{array}{l}7.000977 \\
(4.40539)\end{array}$ & $\begin{array}{c}-5.381639 \\
(5.81161)\end{array}$ & $\begin{array}{c}-1.991782 \\
(5.01936)\end{array}$ \\
\hline $\mathrm{L} 2$ & $\begin{array}{c}-4.756718 \\
(4.17151)\end{array}$ & $\begin{array}{r}-1.148140 \\
(5.90187)\end{array}$ & $\begin{array}{l}1.539089 \\
(4.53134)\end{array}$ & $\begin{array}{l}0.8427163 \\
(5.69368)\end{array}$ & $\begin{array}{c}-7.019992 \\
(4.94556)\end{array}$ \\
\hline L3 & $\begin{array}{l}4.300887 \\
(4.61385)\end{array}$ & $\begin{array}{l}1.098973 \\
(5.76261)\end{array}$ & $\begin{array}{r}-5.782016 \\
(4.45942)\end{array}$ & $\begin{array}{l}3.622646 \\
(5.65865)\end{array}$ & $\begin{array}{r}4.424921 \\
(5.41766)\end{array}$ \\
\hline $\mathrm{L} 4$ & $\begin{array}{c}-4.682226 \\
(4.72272)\end{array}$ & $\begin{array}{l}-3.561131 \\
(5.42382)\end{array}$ & $\begin{array}{c}1.078133 \\
(4.47422)\end{array}$ & $\begin{array}{c}-3.700085 \\
(5.70355)\end{array}$ & $\begin{array}{c}-7.256623 \\
(5.66760)\end{array}$ \\
\hline L5 & $\begin{array}{r}-3.082177 \\
(4.76887)\end{array}$ & $\begin{array}{c}9.458012 \\
(5.45826)\end{array}$ & $\begin{array}{c}-3.866186 \\
(4.19091)\end{array}$ & $\begin{array}{l}0.0341534 \\
(6.02435)\end{array}$ & $\begin{array}{c}-2.922525 \\
(5.54956)\end{array}$ \\
\hline \multicolumn{6}{|c|}{ Exchange rate return } \\
\hline $\mathrm{Ll}$ & $\begin{array}{c}-0.175783 \\
(0.21753)\end{array}$ & $\begin{array}{c}0.437584 \\
(0.25799)\end{array}$ & $\begin{array}{c}-0.291414 \\
(0.24866)\end{array}$ & $\begin{array}{c}0.439126 \\
(0.19050)\end{array}$ & $\begin{array}{c}-0.037015 \\
(0.24979)\end{array}$ \\
\hline $\mathrm{L} 2$ & $\begin{array}{c}0.150516 \\
(0.21630)\end{array}$ & $\begin{array}{c}0.443720 \\
(0.24984)\end{array}$ & $\begin{array}{c}-0.212081 \\
(0.25728)\end{array}$ & $\begin{array}{c}-0.032820 \\
(0.19146)\end{array}$ & $\begin{array}{l}0.095924 \\
(0.23262)\end{array}$ \\
\hline L3 & $\begin{array}{c}-0.267521 \\
(0.22922)\end{array}$ & $\begin{array}{c}-0.475691 \\
(0.26724)\end{array}$ & $\begin{array}{l}0.232605 \\
(0.24993)\end{array}$ & $\begin{array}{c}-0.299533 \\
(0.18394)\end{array}$ & $\begin{array}{c}-0.344220 \\
(0.24029)\end{array}$ \\
\hline $\mathrm{L} 4$ & $\begin{array}{c}0.153912 \\
(0.23201)\end{array}$ & $\begin{array}{c}0.019291 \\
(0.24813)\end{array}$ & $\begin{array}{c}-0.104209 \\
(0.23884)\end{array}$ & $\begin{array}{l}0.322982 \\
(0.19069)\end{array}$ & $\begin{array}{c}0.254912 \\
(0.24888)\end{array}$ \\
\hline L5 & $\begin{array}{l}0.096837 \\
(0.23303)\end{array}$ & $\begin{array}{c}-0.138886 \\
(0.24878)\end{array}$ & $\begin{array}{c}0.171748 \\
(0.23178)\end{array}$ & $\begin{array}{c}-0.248077 \\
(0.19084)\end{array}$ & $\begin{array}{c}-0.059125 \\
(0.23752)\end{array}$ \\
\hline Constant & $\begin{array}{c}4.471015 \\
(9.39785)\end{array}$ & $\begin{array}{c}0.431035 \\
(8.03827)\end{array}$ & $\begin{array}{c}-8.303744 \\
(8.55325) \\
\end{array}$ & $\begin{array}{c}-2.577605 \\
(15.1951)\end{array}$ & $\begin{array}{l}15.47169 \\
(11.0835)\end{array}$ \\
\hline Adjusted $R$-sq & -0.099520 & 0.073591 & -0.047717 & 0.0277 & 0.0123 \\
\hline$F$-statistic & 0.520285 & 1.421015 & 0.758618 & 1.15 & 1.07 \\
\hline$P$ value & 0.8663 & 0.2038 & 0.6665 & 0.3491 & 0.4083 \\
\hline
\end{tabular}

This table reports the results of the regressions of the exchange rate return at the 10-minute frequency on five lags of order flow and five lags of exchange rate returns over the five days in the sample. Standard errors are reported in the parentheses below the coefficient estimates. The $F$-statistics and $P$ value are from the $F$-tests, which indicate lagged order flow coefficients are not jointly different from zero.

TABLE 10: Granger's causality estimation of return (Evans and Lyons [2] data).

\begin{tabular}{lcc}
\hline Daily frequency & Deutsche mark/US dollar & Japanese yen/US dollar \\
\hline Order flow & & $3.44(7.3)$ \\
L1 & $3.58(5.8)$ & $-1.33(9.9)$ \\
L2 & $9.72(7.7)$ & $-5.29(9.8)$ \\
L3 & $-1.75(7.7)$ & $2.87(9.7)$ \\
L4 & $3.29(8.1)$ & $-1.07(7.1)$ \\
L5 & $1.40(5.8)$ & $-0.07(0.16)$ \\
Exchange rate return & & $-0.04(0.17)$ \\
L1 & $-0.074(0.21)$ & $-0.15(0.16)$ \\
L2 & $-0.46(0.21)$ & $0.003(0.17)$ \\
L3 & $0.10(0.21)$ & $0.014(0.13)$ \\
L4 & $-0.06(0.22)$ & $0.002442(0.00131)$ \\
L5 & $-0.10(0.12)$ & -0.059870 \\
Constant & $-0.000515(0.00057)$ & 0.581988 \\
\hline Adjusted $R$-sq & -0.012987 & 0.8227 \\
$F$-statistic & 0.905130 & 0.5339 \\
$P$ value & & \\
\hline
\end{tabular}

This table reports the results of the regressions of the exchange rate returns on five lags of order flow and five lags of exchange rate returns. Standard errors are reported in the parentheses after the coefficients. The $F$-statistics and $P$ value are from the $F$-tests, which indicate lagged order flow coefficients are not jointly different from zero. 
indicates that private information, based on public macro fundamentals, might only temporarily impact on exchange rate variations.

\section{References}

[1] R. K. Lyons, "A simultaneous trade model of the foreign exchange hot potato," Journal of International Economics, vol. 42, no. 3-4, pp. 275-298, 1997.

[2] M. D. D. Evans and R. K. Lyons, "Order flow and exchange rate dynamics," Journal of Political Economy, vol. 110, no. 1, pp. 170180, 2002.

[3] W. P. Killeen, R. K. Lyons, and M. J. Moore, "Fixed versus flexible: lessons from EMS order flow," NBER Working Papers 8491, 2001.

[4] H. Hau, W. Killeen, and M. Moore, "How has the euro changed the foreign exchange market?” DNB Staff Reports 79, 2003.

[5] D. W. Berger, A. P. Chaboud, S. V. Chernenko, E. Howorka, and J. H. Wright, "Order flow and exchange rate dynamics in electronic brokerage system data," International Finance Discussion Papers 830, 2006.

[6] T. Ito and Y. Hashimoto, "Price impacts of deals and predictability of the exchange rate movements," NBER Working Paper 12682, 2006.

[7] D. Rime, U.S. Exchange Rates and Currency Flows, SIFR Research Report Series no. 4, Stockholm Institute for Financial Research, Stockholm, Sweden, 2001.

[8] R. Payne, "Informed trade in spot foreign exchange markets: an empirical investigation," Journal of International Economics, vol. 61, no. 2, pp. 307-329, 2003.

[9] M. Evans and R. Lyons, "Order flow and exchange rate dynamics," BIS Paper 2, 1999.

[10] J. Hasbrouck, "Measuring the information content of stock trades," The Journal of Finance, vol. 46, no. 1, pp. 179-207, 1991.

[11] J. Daníelsson and R. Love, "Feedback trading," International Journal of Finance and Economics, vol. 11, no. 1, pp. 35-53, 2006.

[12] R. Love and R. Payne, "Macroeconomic news, order flows and exchange rates," FMG Discussion Papers dp475, 2003.

[13] M. Evans and R. Lyons, "Understanding order flow," NBER Working Paper 11748, National Bureau of Economic Research, Inc., Cambridge, Mass, USA, 2005. 


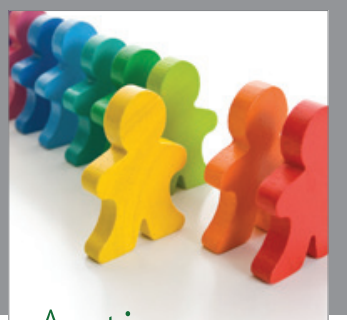

Autism

Research and Treatment
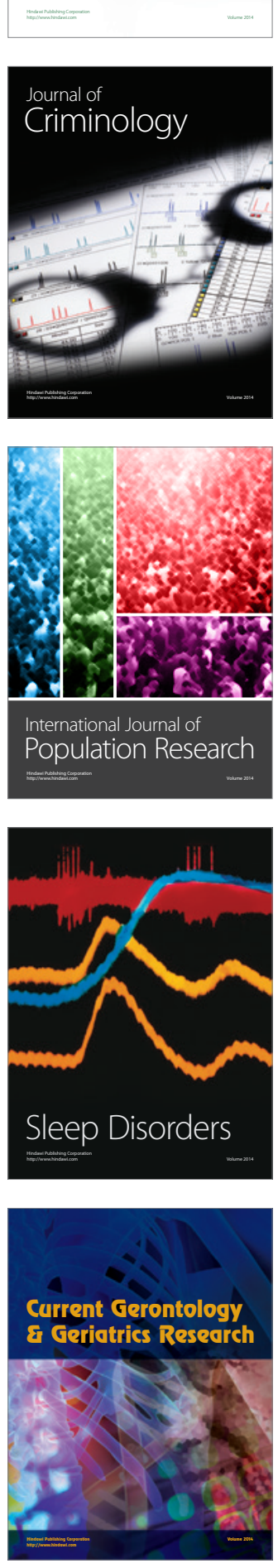
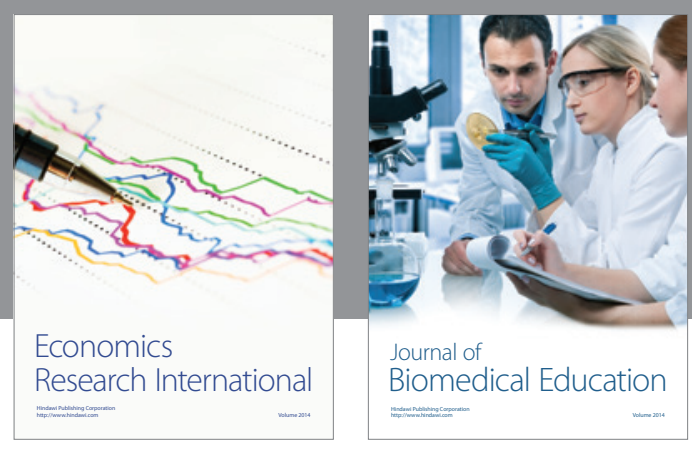

Journal of

Biomedical Education

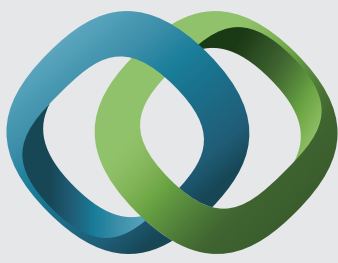

\section{Hindawi}

Submit your manuscripts at

http://www.hindawi.com
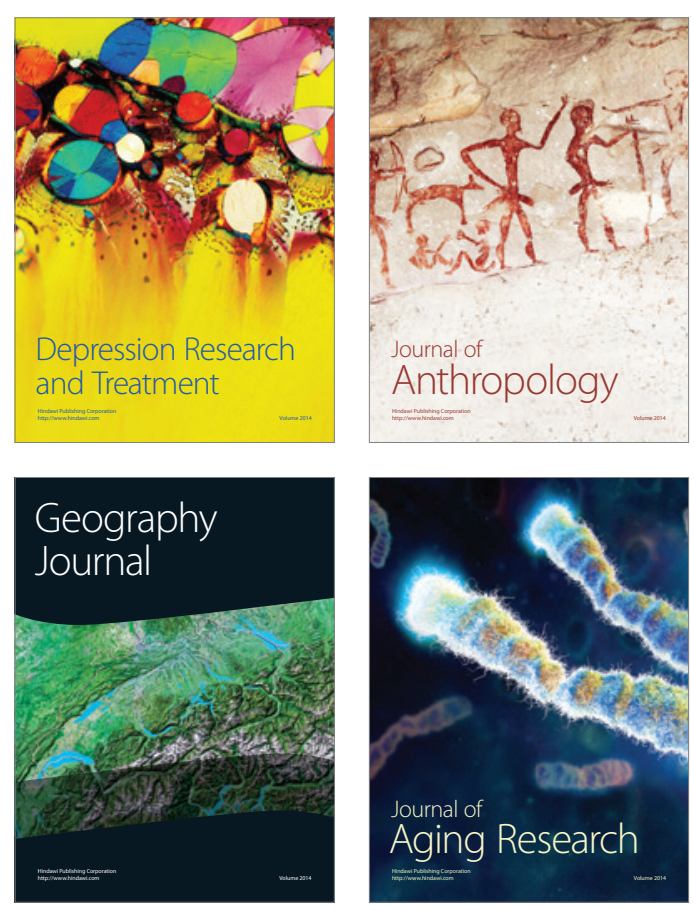

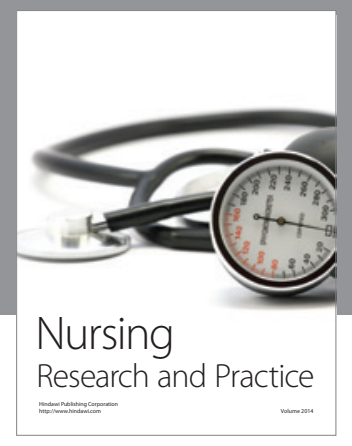

Nursing

Research and Practice

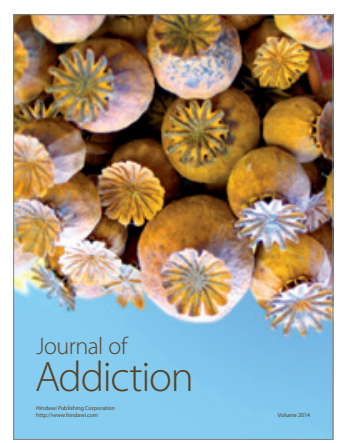

Child Development

Research

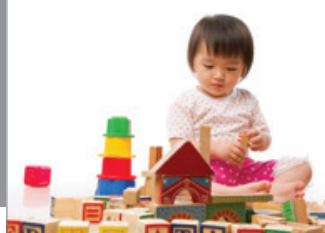

迥
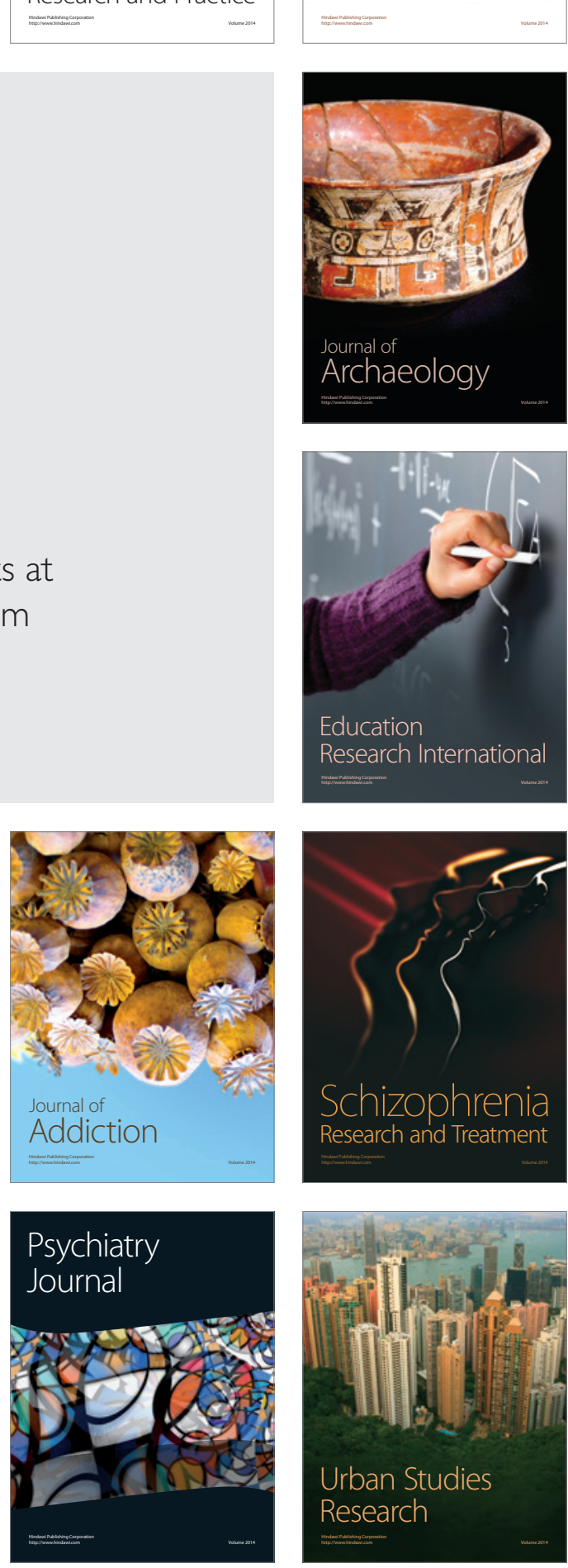